\title{
Formulation, Characterization and In-Vitro Evaluation of Fast Dissolving Oral Films of Cetirizine $\mathrm{HCl}$
}

\author{
Y. Phalguna*1, Haritha Pasupulati ${ }^{1}$, Sandhya Rudra ${ }^{2}$ \\ ${ }^{1}$ Bharat Institute of Technology, Mangalpally(V), Ibrahimpatnam(M), R.R-Dist-501510.Telangana, India. \\ ${ }^{2}$ Bharat school of Pharmacy, Mangalpally(V), Ibrahimpatnam(M), R.R-Dist-501510.Telangana, India.
}

\begin{abstract}
The predominant goal of this work is to formulate and evaluate Cetirizine HCl ODF's the usage of Sodium starch glycolate (SSG) as superdisintegrant, Sodium alginate as polymer and Glycerol as plasticizer. Films were prepared by way of Solvent casting method and evaluated for thickness, folding endurance, percentage elongation, floor $\mathrm{pH}$ and disintegration time. The consequences indicate that method prepared with $17.5 \%$ combo of polymer and plasticizer was determined to be optimized. The three special formulations F1, F2 and F3 of CTZ motion pictures were organized via solvent casting technique the usage of sodium alginate as polymer, SSG as disintegrant and glycerol as plasticizer. Menthol was once used as cooling agent along with aspartame as sweetener and citric acid as a style overlaying agent. The formulation (F3) with presence of superdisintegrant and combo of polymer, plasticizer confirmed first-rate results.
\end{abstract}

Keywords: Cetirizine HCl, Oral thin film, superdisintegrant, polymer, plasticizer

Article Info: Received 11 July 2019; Review Completed 17 August 2019; Accepted 21 August 2019; Available online 30 Aug 2019

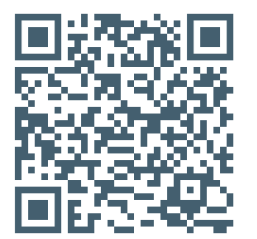

\section{Cite this article as:}

Phalguna Y, Pasupulati H, Rudra S, Formulation, Characterization and In-Vitro Evaluation of Fast Dissolving Oral Films of Cetirizine HCl, Journal of Drug Delivery and Therapeutics. 2019; 9(4-A):122-125 http://dx.doi.org/10.22270/jddt.v9i4A.3392

Dr. Y. Phalguna, Associate Professor, Dept.of Pharmaceutics, Bharat Institute of Technology, Mangalpally(V), Ibrahimpatnam(M), R.R-Dist. Telangana, India. Pincode: 501510

\section{INTRODUCTION}

Fast dissolving oral motion pictures (FDOFs) are the most advanced structure of oral solid dosage shape due to more flexibility and comfort. It improves the efficacy OF APIs with the aid of dissolving inside minute in oral cavity after the contact with saliva besides chewing and no want of water for administration 1 . It gives speedy absorption and on the spot bioavailability of drugs due to excessive blood flow and permeability of oral mucosa is 4-1000 times larger than that of skin. The transport system is truly placed on a patient's tongue or any oromucosal tissue. Instantly moist with the aid of saliva due to presence of hydrophilic polymer and different excipients, the movie swiftly hydrates and dissolves to launch the medicine for oromucosal absorption. Mouth dissolving film is a skinny film with an place of 5$20 \mathrm{~cm}$ containing an active ingredient. The on the spot dissolution, in water or saliva respectively, is reached through a extraordinary matrix from water-soluble polymers. Formulation issues (plasticizers etc) ${ }^{2}$.The delivery system consists of a very thin oral strip, which is actually positioned on the patient's tongue or any oral mucosal tissue, immediately wet by means of saliva the film unexpectedly hydrates and adheres onto the website online of application. It then hastily disintegrates and dissolves to release the medicinal drug for oromucosal absorption or with formula modifications, will maintain the quickdissolving aspects permit for gastrointestinal absorption to be achieved when swallowed. The oral mucosa is composed of an outermost layer of stratified squamous epithelium. Below this lies a basement membrane, a lamina propria accompanied via the submucosa as the innermost layer. The epithelium is similar to stratified squamous epithelia located in the relaxation of the body in that it has a mitotically energetic basal mobile layer, advancing via a variety of differentiating intermediate layers to the superficial layers, the place cells are shed from the floor of the epithelium ${ }^{3}$. The oral mucosa in conventional is intermediate between that of the epidermis and intestinal mucosa in phrases of permeability. It is estimated that the permeability of the buccal mucosa is 4-4000 times increased than that of the skin. Several instructions of pills can be formulated as mouth dissolving motion pictures such as antiulcer (e.g. omeprazole), antiasthamatics (salbutamol sulphate), antitussives, expectorants, and antihistamines, NSAID's (e.g. paracetamol, meloxicam, and valdecoxib). Less bitter, robust and relatively lipophilic drug ought to be favored for OTF4,5. Most superior research has proven that the concentration 
stage of API per dose can prolong up to $50 \%$ per dose weight. Water-soluble polymers are used as movie formers. The use of movie forming polymers in dissolvable motion pictures has attracted considerable interest in medical and nutraceutical application. The water soluble polymers gain rapid disintegration, appropriate mouth experience and mechanical homes to the films 6,7 . The disintegration price of the polymers is reduced by way of growing the molecular weight of polymer film bases. Some of the water soluble polymers used as film former are HPMC E-3 and K-3, Methyl cellulose A-3, A-6 and A-15,Pullulan,carboxmethylcellulosecekol30, Polyvinylpyrollidone PVP K-90, Pectin, Gelatin, Sodium Alginate, Hdroxypropylcellulose, Polyvinyl alcohol, Maltodextrins and EUDRAGIT-RD108-10. By addition of plasticizers, the mechanical residences of system (tensile electricity and elongation) can be improved. Mechanical property is plasticizers concentration established property. The in many instances used plasticizers are glycerol, dibutylpthallate and polyethylene glycols.

\section{MATERIALS AND METHODS}

\section{Materials}

Cetrizine hydrochloride was procured form Aurobindo Pharm., Hyderabad. Sodium alginate and Sodium starch glycolate were purchased from Nihal Traders, Hyderabad. Menthol, Glycerol, Aspartame, Citric acid were purchased from Span Pharma Pvt.Ltd, Hyderabad.

Table no: 1 Formula for Fast Dissolving Oral Film of CTZ

\begin{tabular}{|c|c|c|c|c|}
\hline S.no & Ingredients & Formulation code(F1) & $\begin{array}{c}\text { Formulation } \\
\text { code(F2) }\end{array}$ & $\begin{array}{c}\text { Formulation } \\
\text { code(F3) }\end{array}$ \\
\hline 1 & Cetirizine hydrochloride & 90 & 90 & 90 \\
\hline 2 & Sodium alginate & 100 & 324 & 556 \\
\hline 3 & Glycerol & 150 & 100 & 134 \\
\hline 4 & Menthol & - & - & 10 \\
\hline 5 & Aspartame & - & - & 50 \\
\hline 6 & Sodium starch glycolate & 140 & 80 & 60 \\
\hline 7 & Citric acid & - & 60 & 100 \\
\hline
\end{tabular}

\section{Preparation of Fast Dissolving Oral Film of CTZ}

Oral thin films had been prepared with the aid of solvent casting method. Sodium alginate used to be combined with distilled water with non-stop stirring11. Drug was once delivered to this solution alongside with the cooling agent Plasticizer used to be added to this mixture. Sweetener and taste overlaying agent is then delivered and stirred. Solution was once allowed to stand for 30 minutes. The solution was once then casted on a petri dish. Drying used to be performed for few hours at forty degrees. The motion pictures had been carefully peeled off and saved in air tight plastic containers.

\section{Characterization of Films}

\section{Thickness Film}

The thickness of movie can be measured by means of micrometer screw gauge at exclusive strategic areas (at least 5 locations) ${ }^{12}$. This is vital to determine uniformity in the thickness of the film as this is without delay related to the accuracy of dose in the film.

\section{Folding endurance}

Folding persistence is decided via repeated folding of the movie at the same vicinity till the film breaks. The variety of instances the film is folded without breaking is computed ${ }^{13}$.

\section{Surface $\mathrm{pH}$}

Film was left to swell for 2 hrs on the surface of an agar plate. Agar plate was organized by means of dissolving $2 \%$ $(\mathrm{w} / \mathrm{v})$ agar in warm isotonic phosphate buffer $(\mathrm{pH}$ 6.8) with stirring and then pouring the solution in petridish and allowing it to gel at room temperature ${ }^{14}$. The floor $\mathrm{pH}$ was measured via ability of a $\mathrm{pH}$ paper placed on the floor of the swollen film.

\section{Weight variation}

This take a look at ensures the uniformity of the formed film. Three small portions have been reduce randomly, each of 1 $\mathrm{cm} 2(1 \times 1 \mathrm{~cm})$ areas, and have been weighed individually.

\section{Tensile strength}

Tensile trying out used to be performed the use of a texture analyzer AG/MC1 (Acquati, Italy), geared up with a $5 \mathrm{~N}$ load cell. The movie was reduce into $30 \times 20 \mathrm{~mm}$ strips. Tensile tests have been performed according to ASTM International Test Method for Thin Plastic Sheeting (D882-02). Each check strip was positioned in tensilegrips on the texture analyzer. Initial grip separation was $20 \mathrm{~mm}$ and crosshead pace used to be $1 \mathrm{inch} / \mathrm{min}^{15}$. The take a look at was once regarded concluded when the movie breaks. Tensile strength, used to be computed with assist of load require to destroy the movie and pass sectional region to evaluate tensile homes of the films. Tensile energy (TS) Tensile power is the most stress utilized to a point at which the movie specimen breaks and can be calculated by dividing the maximum load via the unique cross-sectional vicinity of the specimen and it was once expressed in pressure per unit region (MPa). Tensile Strength $=$ Force at damage $(\mathrm{N}) /$ Cross sectional place (mm2).

\section{Mouth dissolving time}

The mouth dissolving time was decided by way of putting the movie manually into a beaker containing $50 \mathrm{ml}$ of 7.4 pHphosphate buffer. Time required by way of the film to dissolve used to be noted.

\section{7. in- vitro Disintegration time}

A small amount of disintegration medium is used. One drop of water was dropped from a $10-\mathrm{ml}$ pipette onto the tightly clamped film. The time taken for the water to make a hole via the film was once measured as disintegration time(DT).

\section{In vitro Dissolution test}

Using Phosphate buffer (ph=6.8) as dissolution medium $(900 \mathrm{ml})$ in paddle type dissolution apparatus in-vitro dissolution of movie is carried out. Temperature is 37 and pace of 60rpm. Film is fixed on a glass slide with assist of adhesive so that drug ought to be released only from top 
surface. Amount withdrawn is replaced. Drug released is calculated.

\section{Stability studies}

The optimized batch F3 was once packed in a butter paper covered with aluminum foil and used to be isothermally harassed to find out about the balance under accelerated temperature and relative humidity prerequisites carried out at $40^{\circ} \mathrm{C} / 75 \% \mathrm{RH}, 25^{\circ} \mathrm{C} / 60 \% \mathrm{RH}$ and $25^{\circ} \mathrm{C} / 40 \% \mathrm{RH}$ for a period of three months. Test samples were withdrawn every month and have been subjected to more than a few checks which include visible inspection of the film, disintegration time and cumulative $\%$ of drug released.

\section{RESULTS AND DISCUSSION}

The physical characterization of the formulated oral videos were completed by using a range of methods cited and the outcomes have been tabulated in Table- 2 for a variety of parameters like weight version of the films, thickness of the films, Tensile electricity of the films, Folding persistence of the films, Disintegration time, Mouth dissolving time, Drug content and invitro dissolution.
Weight variation varies from $42.03 \pm 0.13$ to $52.05 \pm 0.42 \mathrm{mg}$, as the polymer awareness increases the thickness, folding persistence and disintegration time of the movie additionally increases. The formulation F3 shows 33 Sec (disintegration time).

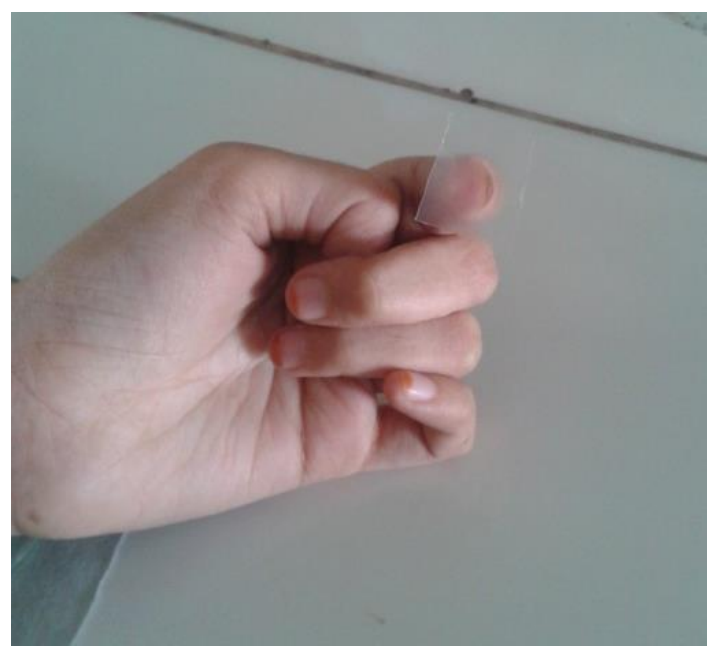

Figure 1. Fast dissolving oral films of CTZ

Table no: 2 Results of Fast Dissolving Oral Film of CTZ

\begin{tabular}{|c|c|c|c|c|}
\hline Formulation code & Thickness Film & Folding endurance & Surface pH & Weight variation \\
\hline F1 & $0.22 \pm 0.08$ & $125 \pm 2.15$ & 6.67 & $52.05 \pm 0.42$ \\
\hline F2 & $0.14 \pm 0.05$ & $95 \pm 1.10$ & 6.69 & $46.07 \pm 0.26$ \\
\hline F3 & $0.10 \pm 0.02$ & $90 \pm 0.95$ & 6.65 & $42.03 \pm 0.13$ \\
\hline
\end{tabular}

Table no: 3 Results of Fast Dissolving Oral Film of CTZ

\begin{tabular}{|c|c|c|c|c|}
\hline Formulation code & $\begin{array}{c}\text { Tensile } \\
\text { strength(Mpa) }\end{array}$ & $\begin{array}{c}\text { Disintegration } \\
\text { Time(sec) }\end{array}$ & $\begin{array}{c}\text { Mouth dissolving } \\
\text { time(sec) }\end{array}$ & Drug content (\%) \\
\hline F1 & $3.51 \pm 0.04$ & $45.12 \pm 1.09$ & $47.85 \pm 2.5$ & $99.4 \%$ \\
\hline F2 & $2.24 \pm 0.08$ & $39.75 \pm 1.50$ & $43.54 \pm 1.8$ & $98.2 \%$ \\
\hline F3 & $1.30 \pm 0.03$ & $33.20 \pm 1.23$ & $40.35 \pm 1.5$ & $97.0 \%$ \\
\hline
\end{tabular}

The formulation F1 suggests the maximum fee of tensile power $3.51 \pm 0.04$ and folding persistence used to be a hundred twenty five This may be due to the formation of sturdy hydrogen bonds between polymer and plasticizer there by means of imparting flexibility to face up to rupture.
The In-vitro drug launch from the method f5 used to be $98.5 \%$ within 7 mins of time and values are given in table-3. The outcomes of the balance studies are given in the table- 4 . Formulation F3 showed cumulative percentage drug release of $99.18 \%$ within 15 min.

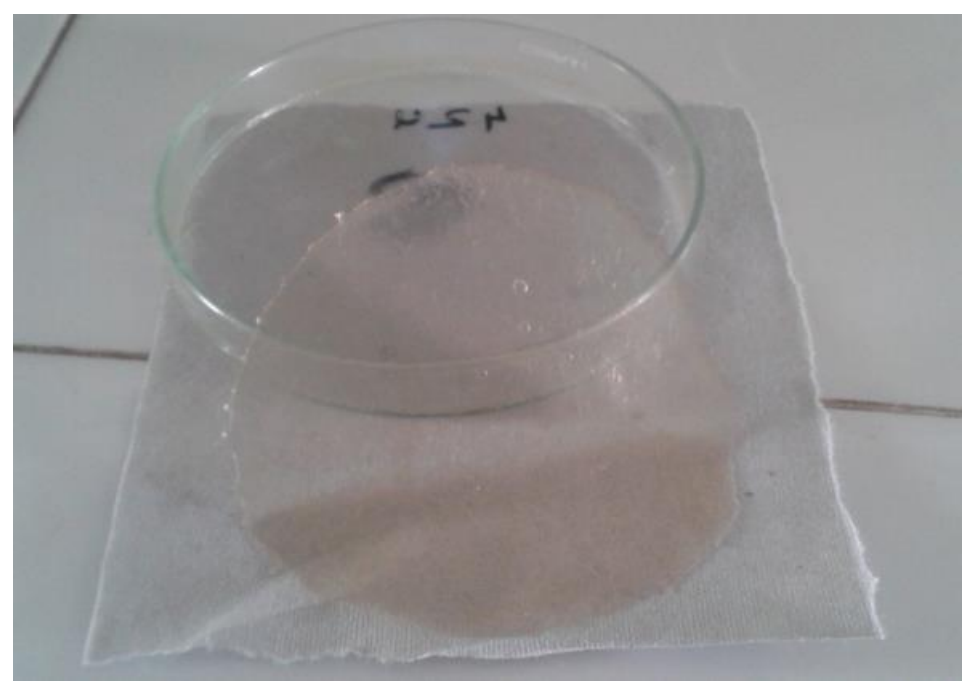

Figure 2. Fast dissolving oral films of CTZ 
Table 4. Stability Studies

\begin{tabular}{|c|c|c|c|c|}
\hline S.no & Time(Days) & Appearance & In-vitro Disintegration time & \%CDR \\
\hline 1 & Initial & $\begin{array}{c}\text { (0 Days) } \\
\text { Transparent and Acceptable }\end{array}$ & $33.48 \pm 3.05$ & $98.8 \%$ \\
\hline 2 & 1 month & $\begin{array}{c}\text { (30 Days) } \\
\text { Transparent and Acceptable }\end{array}$ & $32.15 \pm 2.02$ & $98.2 \%$ \\
\hline 3 & 3 months & $\begin{array}{c}\text { (90 Days) } \\
\text { Transparent and Acceptable }\end{array}$ & $30.25 \pm 2.04$ & $97.1 \%$ \\
\hline
\end{tabular}

\section{CONCLUSION}

The three distinct formulations F1, F2 and F3 of CTZ films had been organized by way of solvent casting approach the use of sodium alginate as polymer, SSG as disintegrant and glycerol as plasticizer. Menthol was used as cooling agent along with aspartame as sweetener and citric acid as a style covering agent. All the videos were evaluated for a number of physical properties such as thickness, weight variation, folding endurance, surface $\mathrm{pH}$, in-vitro release and disintegration time. The bodily parameters had been uniform for all formulations. The components (F3) with presence of superdisintegrant and blend of polymer plasticizer up to complete of $17.5 \%$ showed pleasant results.

\section{ACKNOWLEDGMENTS}

We the authors would like to thank all the authors mentioned below for their study and their contribution on this field. We thank them for the references they provided which helped us in this research study and thankful to management of Bharat Institute of Technology, Hyderabad, Telangana, India.

\section{CONFLICTS OF INTEREST}

No Conflict of Interest

\section{REFERENCES}

1. Priyanka Nagar, Iti Chauhan and Mohd Yasir. Insights into Polymers: Film Formers in Mouth Dissolving Films. Drug Invention Today 2011; 3(12): 280-289.

2. Rajni Bala, Pravin Pawar, Sushi Khanna and Sandeep Arora. Orally dissolving strips: A new approach to oral drug delivery system. International Journal of Pharmaceutical Investigations, April 2013(3): 67-76.

3. Subash vijaya kumar, Basani gavaskar, Guru Sharan, Y. madhusudan rao. Overview on fast dissolving films. International journal of pharmacyand pharmaceutical sciences. 2010; 2(3): 29-33.
4. Aggarwal Jyoti, Singh Gurpreet, Saini Seema, Rana A C. Fast dissolving films: A novel approach to oral drug delivery. International research journal of pharmacy, 2011; 2(12): 69 74.

5. Arun Arya, Amrish Chandra1, Vijay Sharma, Kamla Pathak. Fast Dissolving Oral Films: An Innovative drug delivery System and Dosage Form.International Journal of ChemTech Research. 2010;2(1): 576-583.

6. R.P. Dixit, S.P. Puthli. Oral strip technology: Overview and future potential. Journal of Controlled Release.2009; 139: 94107.

7. Malke M, Shidhaye \& V J Kadam. Formulation and evaluation of Oxacarbazine fast dissolving tablets. Indian journal of pharmaceutical sciences. 2007;69(2): 211-214.

8. Kulkarni A S, Deokule HA, Mane MS, Ghadge DM. Exploration of different polymers for use in the formulation of oral fast dissolving strips. Journal of Current Pharmaceutical Research. 2010; 2(1): 33-35.

9. Priyanka Nagar, Iti Chauhan, Mohd Yasir. Insights into Polymers: Film Formers in Mouth Dissolving Films. Drug Invention Today, 2011, 3(12), 280-289

10. Leduy A, Zajic JE, Luong JHT, Pullulan In: Encyclopedia of Polymer Science and Engineering, 2nd ed., Wiley \& Sons, New York, 1988, 650.

11. Marina K, Charyulu RN, Prabhakara P, Mucoadhesive films of losartan potassium for buccal delivery: Design and characterization, Ind J Pharm Educ Res 44(4), 315-323, 2010.

12. Kumar GV, Krishna RV, William GJ, Konde A, Formulation and evaluation of buccal films of salbutamol sulphate, Ind J Pharm Sci 67(2), 160-164, 2005.

13. Shinde AJ, Garala KC, More HN, Development and characterization of transdermal therapeutics system of tramadol hydrochloride, Asian J Pharm 2(4), 265 - 269,2008.

14. Mashru RC, Sutariya, VB, Sankalia MG, Parikh PP, Development and evaluation of ast-dissolving film of salbutamol sulphate, Drug Dev Ind Pharm 31(1), 25-34, 2005.

15. Renuka M, Avani A, Formulation and characterization of rapidly dissolving films of cetirizine hydrochloride using pullulan as a film forming agent, Ind J Pharm Edu Res 45(1), 71-77, 2011. 